\title{
The influence of blast furnace slag content on the mechanical and durability properties of raw perlite-based geopolymer mortars
}

\author{
Serhat Çelikten \\ Department of Civil Engineering, Nevsehir Haci Bektas Veli University, Nevsehir, 50300, Turkey. \\ Corresponding Author: scelikten@nevsehir.edu.tr
}

Submitted :29/07/2020

Revised : 20/04/2021

Accepted : 28/04/2021

\begin{abstract}
In this work, 21 different raw perlite-(RP)-based geopolymer mortars (RPGMs) were manufactured. Blast furnace slag (BFS) was replaced by RP in 7 different proportions with respect to the $\mathrm{CaO} / \mathrm{SiO}_{2}$ oxide ratio of $\mathrm{RP}$ and BFS mixture in the RPGMs. Sodium hydroxide $(\mathrm{NaOH}=5,10$, and $15 \mathrm{M})$ was used as alkaline medium for geopolymer synthesis in the RPGMs. The ultrasound pulse velocity $\left(U_{p v}\right)$, flexural strength $\left(f_{f s}\right)$ and compressive strength $\left(f_{c s}\right)$, water absorption, and acid and sulfate durability of the RPGMs are investigated. The test results revealed that the BFS improved the mechanical properties of RPGMs for the low and medium alkaline medium of $5 \mathrm{M}$ and 10M, respectively. On the other hand, BFS had negative effect on the mechanical properties of RPGMs produced at a high alkaline medium of $15 \mathrm{M}$. Moreover, the BFS improved the acid and sulfate durability of the RPGMs.
\end{abstract}

Keywords: Perlite; Blast furnace slag; Geopolymer; Mechanical properties; Durability.

\section{INTRODUCTION}

Geopolymers are inorganic polymers synthesized by polymerization of aluminosilicate precursors with alkaline solutions (Ranjbaret al., 2016). The solutions dissolve and release the tetrahedral units of $\left[\mathrm{AlO}_{4}\right]$ and [SiO 4$]$, and these units were linked to the polymeric precursors by sharing oxygen atoms to form the amorphous geopolymers (Timakulet al., 2016). Any materials which are rich in amorphous $\mathrm{Al}$ and $\mathrm{Si}$ can be a potential source for geopolymer precursors (Temuujinet al., 2013; Kaya, 2021; Yurt \& Emiroğlu, 2020). Based on the reaction mechanisms of the precursors, two types of bond systems can be classified (Gao et al., 2017). One is the $(\mathrm{Si}+\mathrm{Ca})$ system; the major reaction product is a C-A-S-H type gel as the main reaction product with a low $\mathrm{Ca} / \mathrm{Si}$ ratio and a high $\mathrm{Al}$ incorporation (Brough \& Atkinson, 2002). The other is the ( $\mathrm{Si}+\mathrm{Al}$ ) system, including primarily N-A-S-H type gels within three-dimensional networks (Liet al., 2010). Due to their differences in gel characteristics and reaction mechanisms, both systems exhibit dissimilar behaviors (Gao et al., 2017). These systems can be synthesized together to achieve higher strength, better durability properties, and a promising future for the application of the geopolymers (Aydın, 2013; T haarrini \& Ramasamy, 2016; Praveen Kumar et al., 2019; and Çelikten et al., 2019). 
Perlite is an igneous rock formed after the cooling of volcanic eruptions, which colors vary from gray to black (de Oliveira et al., 2019). Due to its high amorphous Si and Al content, raw perlite in powder form (RP) can be considered as a precursor material for low Ca geopolymer synthesis (Çelikten \& Isikdag, 2020). However, there are few studies performed on the potential geopolymer production with RP (Çelikten \& Isikdag, 2020; Taxiarchou et al., 2013; and Erdogan, 2015). Besides, these previous works focused on the mechanical properties of RP-based geopolymers, and also RP was used as the sole precursor for geopolymer production. On the other hand, the durability properties of RP-based geopolymers and the properties of geopolymers synthesized from binary or ternary mixtures of RP and high-Ca precursors still need to be investigated.

As stated by the current studies, there is little information in the literature on RP-based geopolymers. Moreover, contrasting with previous studies, that mainly concentrate on the mechanical properties of RP-based geopolymer mortars (RPGMs), the current study evaluates their durability performance in the acid or sulfate environment. In this work, RPGMs were prepared to investigate the mechanical and durability properties of the products. The blast furnace slag (BFS) was substituted by RP in seven different proportions in accordance with the total $\mathrm{CaO} / \mathrm{SiO}_{2}$ oxides available in the RP and $\mathrm{BFS}$. The $\mathrm{NaOH}$ was employed for the production of RPGMs as the sole alkaline activator with three different molarities. This way, the changes in the properties of the RPGMs by the molarity of $\mathrm{NaOH}$ were examined, and the role of BFS in these changes was investigated.

\section{EXPERIMENTAL STUDY}

Raw perlite in powder form (RP), from Genper Mining Industry Trade Co., Kütahya Province, Western Turkey, was employed as the main precursor material for the RP-based geopolymer mortars (RPGMs). Blast furnace slag (BFS) was provided from Karçimsa Cement Industry located in Karabük Province, Northern Turkey. The BFS was used in the RPGMs as partial replacement precursor material by the RP. The chemical compositions of the precursor materials (RP and BFS) are given in Table 1. The specific gravities of RP and BFS were 2.54 and 2.86, respectively. Besides, the blaine specific surface areas of RP and BFS were about 3850 and $4000 \mathrm{~cm}^{2} / \mathrm{g}$, respectively. The $\mathrm{NaOH}$ was in solid form with $>96 \%$ purity but was used in the RPGMs as the sole alkaline activator after dissolving in water to obtain the desired molarities of 5, 10, and 15 Molar (M). Standard sand identified by CEN (Committee of European Norms) in the EN 196-1 was used for the production of the RPGMs. The grading of the sand is given in Table 2 .

Table 1. Chemical compositions of precursors.

\begin{tabular}{|c|c|c|c|c|c|c|c|c|c|}
\hline Oxide (\%) & $\mathrm{SiO}_{2}$ & $\mathrm{CaO}$ & $\mathrm{Al}_{2} \mathrm{O}_{3}$ & $\mathrm{Fe}_{2} \mathrm{O}_{3}$ & $\mathrm{SO}_{3}$ & $\mathrm{Na}_{2} \mathrm{O}$ & $\mathrm{K}_{2} \mathrm{O}$ & $\mathrm{MgO}$ & Loss of ignition \\
\hline Blast furnace slag & 32.47 & 32.45 & 9.94 & 1.25 & 0.82 & 0.31 & 0.85 & 9.31 & 0.46 \\
\hline Perlite & 71.36 & 0.96 & 13.08 & 0.78 & 0.12 & 3.21 & 5.42 & 0.12 & 2.12 \\
\hline
\end{tabular}

Table 2. The grading of sand.

\begin{tabular}{|c|c|c|c|c|c|c|}
\hline Sieve Size (mm) & $\mathbf{2 . 0}$ & $\mathbf{1 . 6}$ & $\mathbf{1 . 0}$ & $\mathbf{0 . 5 0}$ & $\mathbf{0 . 1 6}$ & $\mathbf{0 . 0 8}$ \\
\hline Cumulative percentage & 0 & 7 & 32 & 68 & 87 & 99 \\
\hline
\end{tabular}


A total of 21 RPGM mixtures were prepared by varying the RP, BFS, and $\mathrm{NaOH}$ contents. The water and sand contents were kept constant to investigate the effect of the activator and precursor (RP and BFS) contents. The proportion of water to total precursor content (RP+BFS) ratio was 1:2, and the proportion of sand to precursor content was $3: 1$. The molarity variations of $\mathrm{NaOH}$ in the mixtures were 5,10 , and $15 \mathrm{M}$. The BFS was replaced by $\mathrm{RP}$ according to the total $\mathrm{CaO} / \mathrm{SiO}_{2}$ oxide ratio of these precursors. The $\mathrm{CaO} / \mathrm{SiO}_{2}$ ratio of the precursors was designed as the increasing rate from 0.01 (RP as sole precursor) to 0.30 . The mixture proportions of RPGMs for the three-cell mortar mould are shown in Table 3. As shown in the table, the RPGM mixtures were coded as the molarity of $\mathrm{NaOH}$ and the $\mathrm{CaO} / \mathrm{SiO}_{2}$ ratio of the precursors, respectively. Besides, the mixing procedures of RPGMs involved the following steps. The $\mathrm{NaOH}$ solution and RP+BFS mixture were put in the mixing bowl of Hobart mixer and mixed at $140 \mathrm{rpm}$ (revolutions per minute) for 30 seconds. After the first 30 seconds, the sand was poured into the bowl for 30 seconds during mixing. Then, the mixture was mixed at $280 \mathrm{rpm}$ for 30 seconds. After that, the mixture was left in the bowl at a non-operating state for 90 seconds. Then, the mixture was mixed at $280 \mathrm{rpm}$ for 60 seconds. Finally, the mixture was cast into $4 \times 4 \times 16 \mathrm{~cm}$ molds after waiting for 15 seconds in compliance with the EN 196-1 standard. Immediately after casting, the RPGMs were subjected to heat-curing in an oven at $100^{\circ} \mathrm{C}$ without being covered for 24 hours. Twenty-four $4 \times 4 \times 16 \mathrm{~cm}$ mortar specimens were obtained from each mixture to use the mechanical and durability tests. Three RPGM specimens were employed for each test and the final test results were obtained from averaging of three values obtained from the three specimens.

Table 3. Mix proportions of the mortars.

\begin{tabular}{|c|c|c|c|c|c|c|c|}
\hline $\begin{array}{c}\text { Serial } \\
\text { code }\end{array}$ & $\begin{array}{l}\text { Mixture } \\
\text { code }\end{array}$ & $\begin{array}{r}\mathbf{R P} \\
(\mathrm{g})\end{array}$ & $\begin{array}{c}\text { BFS } \\
(\mathrm{g})\end{array}$ & $\begin{array}{c}\mathrm{NaOH} \\
(\mathrm{g})\end{array}$ & $\begin{array}{l}\text { Sand } \\
(\mathrm{g})\end{array}$ & $\begin{array}{c}\text { Water } \\
\text { (g) }\end{array}$ & $\begin{array}{c}\mathrm{CaO} / \mathrm{SiO}_{2} \\
\text { ratio of } \\
\text { precursors }\end{array}$ \\
\hline \multirow{7}{*}{$5 \mathrm{M}$} & $5 \mathrm{M}-0.01$ & 450 & 0 & 45 & 1350 & 225 & 0.01 \\
\hline & 5M-0.05 & 414 & 36 & 45 & 1350 & 225 & 0.05 \\
\hline & $5 \mathrm{M}-0.10$ & 369 & 81 & 45 & 1350 & 225 & 0.10 \\
\hline & $5 \mathrm{M}-0.15$ & 333 & 117 & 45 & 1350 & 225 & 0.15 \\
\hline & $5 \mathrm{M}-0.20$ & 297 & 153 & 45 & 1350 & 225 & 0.20 \\
\hline & $5 \mathrm{M}-0.25$ & 266 & 184 & 45 & 1350 & 225 & 0.25 \\
\hline & $5 \mathrm{M}-0.30$ & 239 & 211 & 45 & 1350 & 225 & 0.30 \\
\hline \multirow{7}{*}{$10 \mathrm{M}$} & $10 \mathrm{M}-0.01$ & 450 & 0 & 90 & 1350 & 225 & 0.01 \\
\hline & $10 \mathrm{M}-0.05$ & 414 & 36 & 90 & 1350 & 225 & 0.05 \\
\hline & $10 \mathrm{M}-0.10$ & 369 & 81 & 90 & 1350 & 225 & 0.10 \\
\hline & $10 \mathrm{M}-0.15$ & 333 & 117 & 90 & 1350 & 225 & 0.15 \\
\hline & $10 \mathrm{M}-0.20$ & 297 & 153 & 90 & 1350 & 225 & 0.20 \\
\hline & $10 \mathrm{M}-0.25$ & 266 & 184 & 90 & 1350 & 225 & 0.25 \\
\hline & $10 \mathrm{M}-0.30$ & 239 & 211 & 90 & 1350 & 225 & 0.30 \\
\hline \multirow{7}{*}{$15 \mathrm{M}$} & $15 \mathrm{M}-0.01$ & 450 & 0 & 135 & 1350 & 225 & 0.01 \\
\hline & $15 \mathrm{M}-0.05$ & 414 & 36 & 135 & 1350 & 225 & 0.05 \\
\hline & $15 \mathrm{M}-0.10$ & 369 & 81 & 135 & 1350 & 225 & 0.10 \\
\hline & $15 \mathrm{M}-0.15$ & 333 & 117 & 135 & 1350 & 225 & 0.15 \\
\hline & $15 \mathrm{M}-0.20$ & 297 & 153 & 135 & 1350 & 225 & 0.20 \\
\hline & $15 \mathrm{M}-0.25$ & 266 & 184 & 135 & 1350 & 225 & 0.25 \\
\hline & $15 \mathrm{M}-0.30$ & 239 & 211 & 135 & 1350 & 225 & 0.30 \\
\hline
\end{tabular}


The ultrasonic pulse velocity $\left(U_{p v}\right)$, flexural strength $\left(f_{f s}\right)$, compressive strength $\left(f_{c s}\right)$, and water absorption tests were performed on the RPGMs after 24 hours from the heat-curing process. The $U_{p v}$ tests were conducted according to ASTM C597-16. The accuracy of $U_{p v}$ test was $0.10 \mathrm{~s}$. The $f_{c s}$ and $f_{f s}$ tests were executed with a universal testing machine in compliance with TS EN 1015-11. The $f_{f s}$ tests were conducted on the RPGMs in center-point (i.e., three-point) loading conditions. The semi-prisms were broken after the $f_{f s}$ tests were used for the $f_{c s}$ tests. The $f_{c s}$ tests were conducted by placing $4 \times 4 \mathrm{~cm}$ thin steel plates on the both top and bottom of broken specimens. The water absorption test was performed on the RPGMs according to ASTM C 642-06 standard. Besides, six specimens for each RPGM mixture were immersed in $\mathrm{HCl}$ solution $(\mathrm{pH}=2), 5 \% \mathrm{Na}_{2} \mathrm{SO}_{4}$, and $5 \%$ $\mathrm{MgSO}_{4}$ solutions for 90 and 180 days, separately. The $f_{c s}$ test was conducted on these specimens after immersion in the solutions. Finally, the residual $f_{c s}$ values of the RPGMs were calculated with the following equation:

Residual $f_{c s}(\%)=\left[\left(f_{c s i}-f_{c s f}\right) / f_{c s i}\right] \times 100$

where $\mathrm{f}_{\text {csi }} / \mathrm{f}_{\text {csf }}$ are the $f_{c s}$ of the RPGM specimens unexposed/exposed to acid or sulfate, solutions, respectively.

\section{RESULTS AND DISCUSSIONS}

Figure 1 and Table 4 report the Upv results of the RPGMs. The Upv of RPGMs was affected by the amount of BFS and molarity of $\mathrm{NaOH}$, significantly. The Upv values of RPGMs made with $5 \mathrm{M}, 10 \mathrm{M}$, and $15 \mathrm{M} \mathrm{NaOH}$ solution were in the range of $2.2-3.5 \mathrm{~km} / \mathrm{sec}$., $2.6-3.4 \mathrm{~km} / \mathrm{sec}$., and $2.6-2.9 \mathrm{~km} / \mathrm{sec}$., respectively. It was clear that an increase in $\mathrm{NaOH}$ content led to improved Upv for RPGMs made with only $\mathrm{RP}$ as a precursor $(\mathrm{CaO} / \mathrm{SiO} 2$ ratio is 0.01). The observed improvement in the Upv of these RPGMs by including higher $\mathrm{NaOH}$ can be attributed to the development of a more compact microstructure and a better activation of RP at high alkali concentration as reported in previous studies (Çelikten \& Isikdag, 2020; Erdogan, 2015). The BFS caused to increase the Upv of RPGMs. Moreover, the BFS content became more effective as the $\mathrm{NaOH}$ concentration decreased. The Upv of RPGMs was enhanced up to $59 \%, 30 \%$, and $7.5 \%$ by increasing $\mathrm{CaO} / \mathrm{SiO} 2$ ratio of the precursors (RP and $\mathrm{BFS}$ ) from 0.01 to 0.3 at $5 \mathrm{M}, 10 \mathrm{M}$, and $15 \mathrm{M}$ alkaline medium, respectively. It was previously reported that Upv of mortars decreased with porosity (Mendes et al., 2020; Lafhaj \& Goueygou, 2009). Also, it was indicated that the geopolymers made with precursors having low $\mathrm{CaO} / \mathrm{SiO}_{2}$ ratio have more porous microstructure than the geopolymers produced with a high $\mathrm{CaO} / \mathrm{SiO}_{2}$ ratio (Luna Galiano et al., 2016). These results were compatible with the decrease in the $U_{p v}$ of RPGMs as $\mathrm{BFS}$ or $\mathrm{CaO} / \mathrm{SiO}_{2}$ ratio increased.

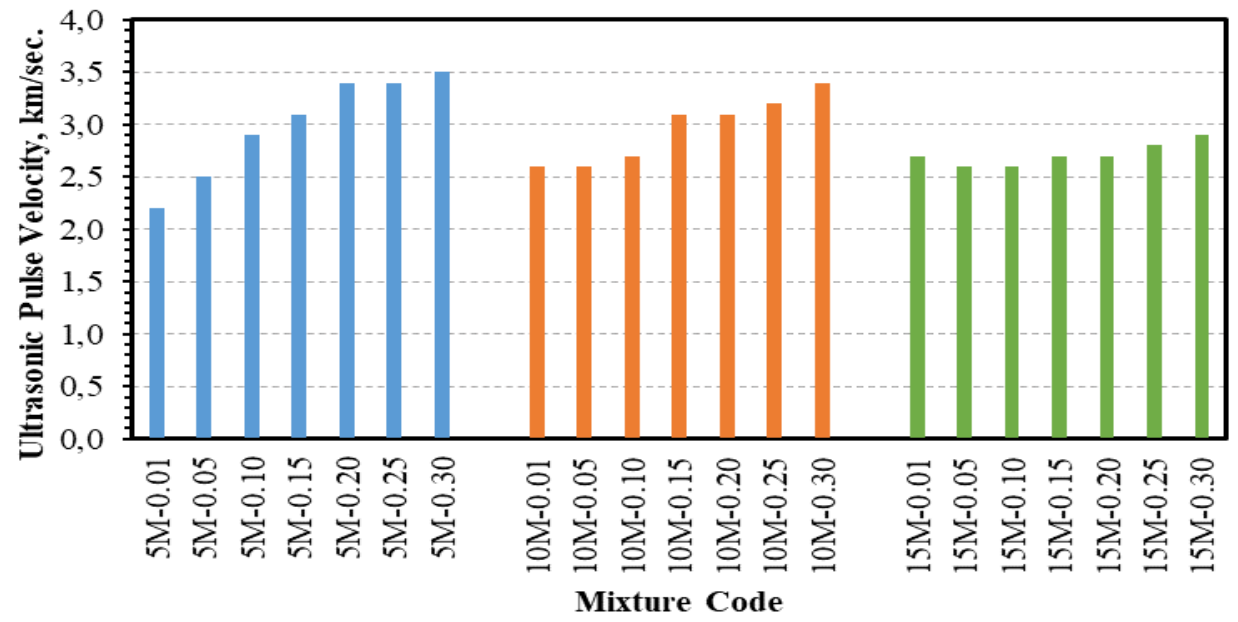

Figure 1. Ultrasonic pulse velocity results of RPGMs. 
The $f_{f s}$ results in the various RPGMs are plotted in Figure 2 and Table 4 with varying $\mathrm{CaO} / \mathrm{SiO}_{2}$ ratios and $\mathrm{NaOH}$ concentrations. From the results, it could be observed that both alkali content of $\mathrm{NaOH}$ solution and replacement level of BFS by RP had an important influence on the $f_{f s}$ development of the RPGMs. The $f_{f s}$ values of RPGMs in the series of $5 \mathrm{M}, 10 \mathrm{M}$, and $15 \mathrm{M} \mathrm{NaOH}$ solution were in the intervals of 2.5-3.4 MPa, 4.7-5.1 MPa, and 3.0-5.9 MPa, respectively. The $f_{f s}$ values of RPGMs were enhanced by increasing the molarity of $\mathrm{NaOH}$ from $5 \mathrm{M}$ to $10 \mathrm{M}$, significantly. The enhancement was more distinct for the RPGMs having $\mathrm{CaO} / \mathrm{SiO}_{2}$ ratios of 0.01 and 0.05 . On the other hand, $f_{f s}$ values of the RPGMs made with $\mathrm{CaO} / \mathrm{SiO}_{2}$ ratio above 0.1 decreased by increasing the molarity of $\mathrm{NaOH}$ from $10 \mathrm{M}$ to $15 \mathrm{M}$. The $f_{f s}$ values of the $15 \mathrm{M}-0.25$ and $15 \mathrm{M}-0.30$ RPGMs were almost $38 \%$ lower than the 10M-0.25 and 10M-0.30 RPGMs. These results indicate that the activation of BFS was negatively influenced by the $\mathrm{NaOH}$ concentration higher than $10 \mathrm{M}$. It can be said that the RP showed better activation in a high alkaline medium with respect to the BFS. Besides, the highest $f_{f s}$ of $5.9 \mathrm{MPa}$ was achieved for the $15 \mathrm{M}-0.01$ mortars in all the RPGMs.

Table 4. Test results of the RPGMs.

\begin{tabular}{|c|c|c|c|c|c|c|c|c|c|c|}
\hline 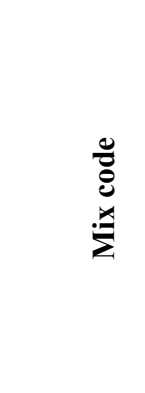 & 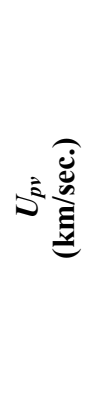 & $4 \sum^{\overparen{E}}$ & $v^{\overparen{E}}$ & 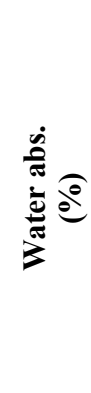 & 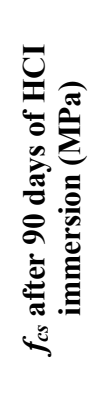 & 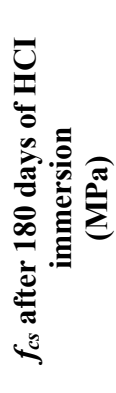 & 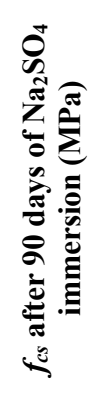 & 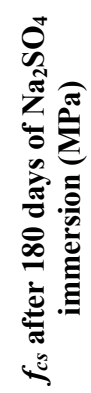 & 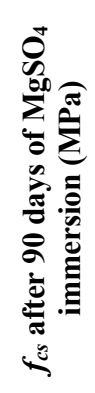 & 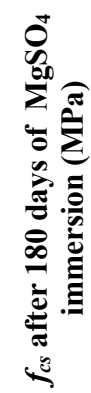 \\
\hline $5 \mathrm{M}-0.01$ & 2.2 & 2.5 & 11.6 & 11.3 & 4.0 & 3.6 & 4.2 & 3.7 & 4.1 & 3.4 \\
\hline $5 \mathrm{M}-0.05$ & 2.5 & 2.6 & 12.2 & 11.0 & 4.3 & 3.8 & 4.5 & 3.9 & 4.3 & 3.9 \\
\hline $5 \mathrm{M}-0.10$ & 2.9 & 3.3 & 15.3 & 10.4 & 5.8 & 4.7 & 6.1 & 5.0 & 5.7 & 4.8 \\
\hline $5 \mathrm{M}-0.15$ & 3.1 & 3.4 & 17.4 & 9.6 & 8.0 & 7.1 & 8.8 & 7.4 & 7.7 & 6.9 \\
\hline $5 \mathrm{M}-0.20$ & 3.4 & 3.4 & 18.8 & 8.8 & 9.3 & 8.4 & 9.5 & 8.7 & 9.2 & 8.4 \\
\hline $5 \mathrm{M}-0.25$ & 3.4 & 3.2 & 20.1 & 8.1 & 10.4 & 9.1 & 10.5 & 9.4 & 10.3 & 9.4 \\
\hline $5 \mathrm{M}-0.30$ & 3.5 & 3.4 & 22.5 & 7.6 & 11.7 & 10.3 & 12.2 & 10.6 & 11.5 & 10.1 \\
\hline $10 \mathrm{M}-0.01$ & 2.6 & 5.1 & 20.8 & 10.9 & 5.1 & 4.2 & 5.4 & 4.5 & 4.9 & 4.1 \\
\hline $10 \mathrm{M}-0.05$ & 2.6 & 4.8 & 21.3 & 10.7 & 5.0 & 4.1 & 5.8 & 4.8 & 5.1 & 4.3 \\
\hline $10 \mathrm{M}-0.10$ & 2.7 & 4.7 & 21.9 & 10.3 & 7.3 & 6.1 & 7.9 & 6.6 & 7.1 & 5.9 \\
\hline $10 \mathrm{M}-0.15$ & 3.1 & 4.9 & 22.5 & 9.3 & 7.5 & 6.3 & 10.5 & 8.8 & 8.7 & 7.3 \\
\hline $10 \mathrm{M}-0.20$ & 3.1 & 4.7 & 22.6 & 8.9 & 9.7 & 8.1 & 11.2 & 9.4 & 9.6 & 8.0 \\
\hline $10 \mathrm{M}-0.25$ & 3.2 & 5.0 & 24.3 & 8.3 & 10.3 & 8.6 & 12.6 & 10.5 & 10.9 & 9.1 \\
\hline $10 \mathrm{M}-0.30$ & 3.4 & 4.8 & 24.8 & 7.8 & 11.0 & 9.2 & 13.0 & 10.8 & 11.1 & 9.3 \\
\hline $15 \mathrm{M}-0.01$ & 2.7 & 5.9 & 23.6 & 10.2 & 5.3 & 4.1 & 5.6 & 4.3 & 5.2 & 4.1 \\
\hline $15 \mathrm{M}-0.05$ & 2.6 & 5.2 & 23.4 & 10.0 & 5.2 & 4.0 & 5.5 & 4.2 & 5.1 & 4.2 \\
\hline $15 \mathrm{M}-0.10$ & 2.6 & 4.7 & 23.0 & 9.8 & 6.4 & 5.3 & 6.7 & 5.6 & 6.3 & 5.3 \\
\hline
\end{tabular}




\begin{tabular}{|l|l|l|l|l|l|l|l|l|l|l|}
\hline $15 \mathrm{M}-0.15$ & 2.7 & 4.4 & 21.2 & 9.7 & 6.5 & 5.7 & 6.9 & 6.0 & 6.6 & 5.8 \\
\hline $15 \mathrm{M}-0.20$ & 2.7 & 3.9 & 20.8 & 9.4 & 6.8 & 6.0 & 7.1 & 6.3 & 7.0 & 5.8 \\
\hline $15 \mathrm{M}-0.25$ & 2.8 & 3.1 & 18.9 & 9.0 & 7.1 & 6.2 & 7.5 & 6.5 & 7.0 & 5.9 \\
\hline $15 \mathrm{M}-0.30$ & 2.9 & 3.0 & 18.3 & 8.7 & 7.6 & 6.1 & 7.9 & 6.4 & 7.7 & 6.1 \\
\hline
\end{tabular}

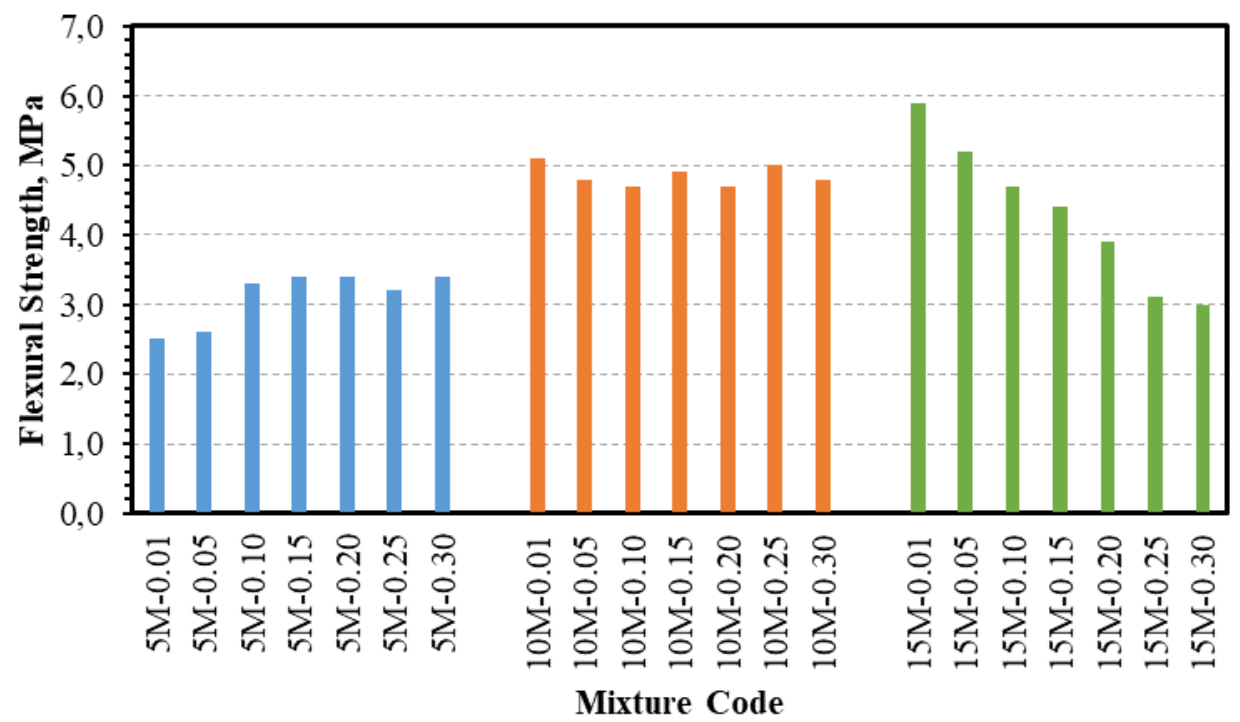

Figure 2. Flexural strength results of RPGMs.

Figure 3 and Table 4 show the $f_{c s}$ test results of the RPGMs. The highest $f_{c s}$ of $24.8 \mathrm{MPa}$ was recorded for 10M-0.30 RPGMs. The $f_{c s}$ values of the RPGMs made by using RP as the sole precursor $\left(\mathrm{CaO} / \mathrm{SiO}_{2}=0.01\right)$ improved by increasing $\mathrm{NaOH}$ content. The $f_{c s}$ increase was $79 \%$ and $13 \%$ in these RPGMs from $5 \mathrm{M}$ to $10 \mathrm{M}$ and from $10 \mathrm{M}$ to $15 \mathrm{M}$, respectively. With increasing concentration of $\mathrm{NaOH}$ in the RPGMs, the solubilities of amorphous $\mathrm{Si}$ and $\mathrm{Al}$ in RP also increased as stated in previous works for fly ash (Çelikten \& Isikdag, 2020) and calcined clay (El Hafidet al., 2017) as another low Ca precursors. The $f_{c s}$ values of the RPGMs significantly increased by increasing the $\mathrm{CaO} / \mathrm{SiO}_{2}$ ratio or the BFS content for the $5 \mathrm{M} \mathrm{NaOH}$ medium. On the other hand, the $f_{c s}$ values of RPGMs decreased by increasing the BFS content at $15 \mathrm{M}$ alkaline medium. These results indicate that the $15 \mathrm{M} \mathrm{NaOH}$ content negatively influenced the dissolution of $\mathrm{Si}$ and $\mathrm{Al}$ species from the BFS. The lower dissolution of these species can be attributed to the excessive $\mathrm{OH}^{-}$(Part et al., 2015; Cho et al., 2017) or excessive $\mathrm{Na}^{+}$(Sun et al., 2018) adsorbed on the surface of fly ash particles as stated for fly ash-based geopolymers in the previous works. The optimum alkaline concentration varies from one precursor to another due to their different solubility and degree of amorphousness. For example, in previous works, $12 \mathrm{M} \mathrm{NaOH}$ was reported as appropriate molarity for ceramic sanitary ware waste-based geopolymers (Atabey \& Ozturk, 2020) and 16M for expanded perlite-based geopolymer mortars (Çelikten \& Isikdag, 2020). In the present work, BFS exhibits better activation than the RP in a low alkaline medium. Additionally, $f_{f s} / f_{c s}$ ratios of the RPGMs were gradually decreased by increasing BFS content. The ratios were $0.21,0.24$, and 0.25 for the $5 \mathrm{M}-0.01,10 \mathrm{M}-0.01$, and $15 \mathrm{M}-0.01 \mathrm{RPGMs}$, respectively. On the other hand, 5M-0.30, 10M-0.30, and 15M-0.30 RPGMs had $f_{f s} / f_{c s}$ ratios of 0.15, 0.19, and 0.16, respectively. The reason for the decrease in the ratio with BFS inclusion can be attributed to the sensitivity of BFS to the heatcuring process. 


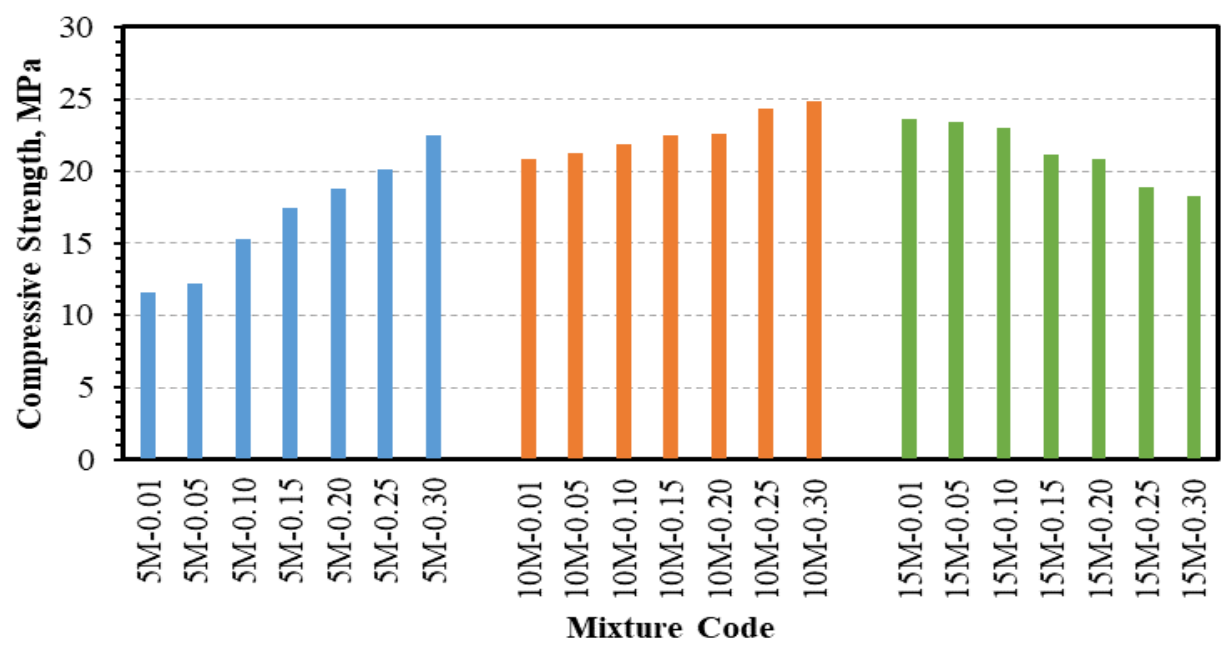

Figure 3. Compressive strength results of RPGMs.

The influence of $\mathrm{CaO} / \mathrm{SiO}_{2}$ ratio and $\mathrm{NaOH}$ content on the water absorption of RPGMs is shown in Figure 4 and Table 4. It can be seen from this figure that the water absorption capacity of RPGMs increased by increasing the $\mathrm{CaO} / \mathrm{SiO}_{2}$ ratio independent of the $\mathrm{NaOH}$ molarity. Besides, the water absorption capacity of the RPGMs, which have $\mathrm{CaO} / \mathrm{SiO}_{2}$ ratio lower than 0.15 , decreased gradually by increasing the molarity of $\mathrm{NaOH}$. However, the capacity of the RPGMs designed with the $\mathrm{CaO} / \mathrm{SiO}_{2}$ ratios of $0.20,0.25$, and 0.30 increased with the increasing $\mathrm{NaOH}$ molarity. These results were compatible with the $U_{p v}$ results. These results are likely to be related to the better activation of BFS at low $\mathrm{NaOH}$ molarity resulting in low pore volume for the RPGMs. In a previous work (Yusuf et al., 2014), it was reported that the increase in the Ca content by the inclusion of BFS in the low Ca geopolymer system (ultrafine palm oil fuel ash-based geopolymer was studied in the previous work) caused the density of the products to increase through pore filling effect. As stated in other previous studies, the utilization of BFS by fly ash in the low Ca geopolymer systems gave a decrease in total porosity (Proviset al., 2012) and caused to a decrease in the water absorption capacity (Sarıdemir \& Çelikten, 2020). In the present work, $U_{p v}$ and water absorption results indicate the filling effect of BFS in the RPGMs as stated in the previous works.

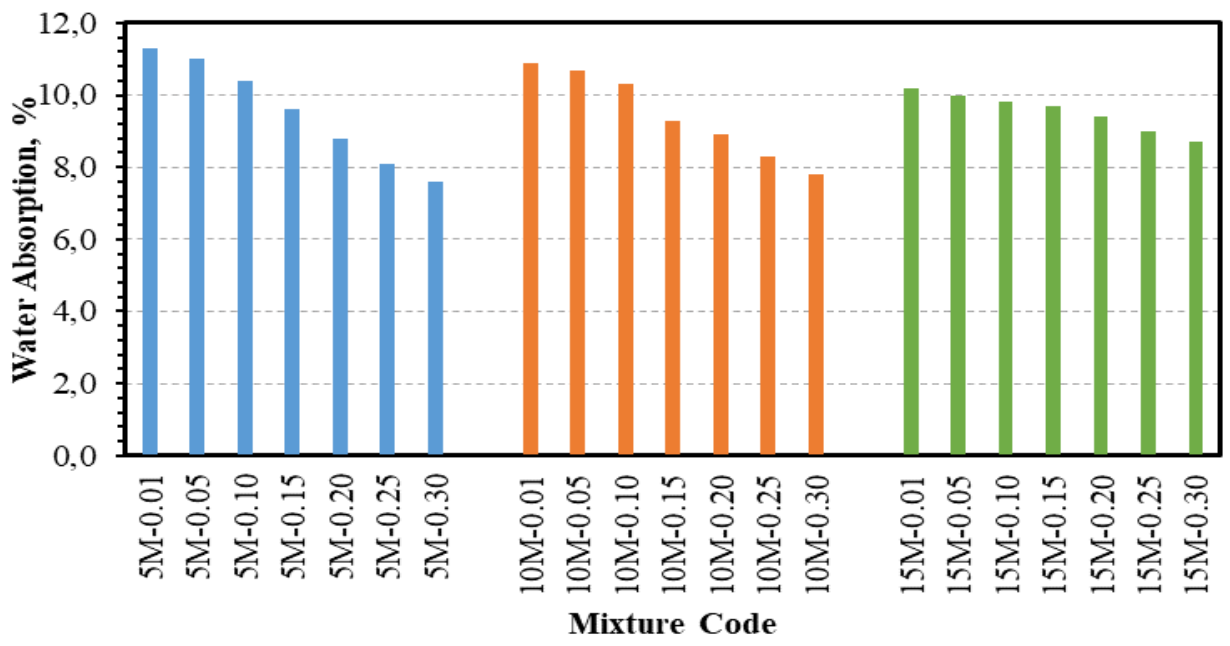

Figure 4. Water absorption results of RPGMs. 
The acid resistance of the RPGMs was evaluated based on the change in $f_{c s}$ of mortar specimens after exposure to $\mathrm{HCl}$ solution $(\mathrm{pH}=2)$ for 90 and 180 days, separately. Figure 5 and Table 4 show the residual $f_{c s}$ and final $f_{c s}$ results of RPGMs after immersion of the $\mathrm{HCl}$ solution, respectively. The residual $f_{c s}$ of the $5 \mathrm{M}-0.01 \mathrm{RPGMs}$ decreased to about $34.5 \%$ and $31 \%$ for 90 and 180 days of immersion periods, respectively. The inclusion of BFS increased the residual $f_{c s}$ of the RPGMs. The highest residual $f_{c s}$ values were observed on the $5 \mathrm{M}-0.30$ as $52 \%$ and 45.8\% after immersion for 90 and 180 days, respectively. The improved durability of the RPGMs to the acid environment with the BFS content can be attributed to the difficult diffusion of $\mathrm{H}^{+}$ions to the inner structure of the mortars. The difficulty in the diffusion of the ions may be originated from the change in the pore structure of the RPGMs with BFS content as supported by $U_{p v}$ and water absorption results. Besides, the residual $f_{c s}$ of the RPGMs decreased by increasing the molarity of $\mathrm{NaOH}$ due to the lower activation of $\mathrm{BFS}$ in high molarities. The lowest residual $f_{c s}$ values were observed on the $15 \mathrm{M}-0.01$ and $15 \mathrm{M}-0.05$ RPGMs. On the other hand, $f_{c s}$ values of these RPGMs were still higher than the 5M-0.01 and 5M-0.05 RPGMs after immersion in $\mathrm{HCl}$ solution.

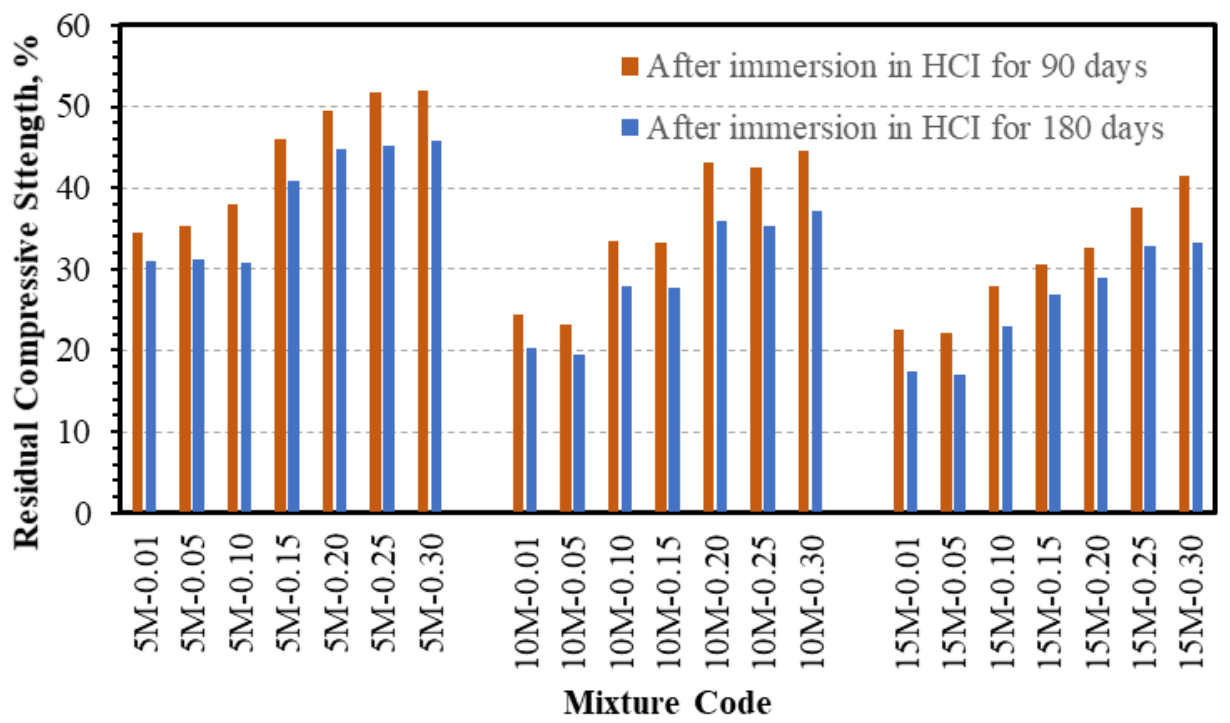

Figure 5. Residual compressive strengths of RPGMs after exposure to acid.

The residual $f_{c s}$ and final $f_{c s}$ values of the RPGMs after exposure to $5 \% \mathrm{Na}_{2} \mathrm{SO}_{4}$ solution for 90 and 180 days are given in Figure 6 and Table 4, respectively. The residual $f_{c s}$ values were in the ranges of 36-55\%, 26-53\%, and $23-43 \%$ for the RPGMs in the series of $5 \mathrm{M}, 10 \mathrm{M}$, and $15 \mathrm{M}$ after exposure to $\mathrm{Na}_{2} \mathrm{SO}_{4}$ solution for 90 days. After immersion for 180 days, the values were decreased between $4 \%$ and $9 \%$ with respect to the proportions calculated after 90 days of immersion. The highest residual $f_{c s}$ values were observed on the RPGMs manufactured as the $\mathrm{CaO} / \mathrm{SiO}_{2}$ ratio of 0.30 in all the series. The highest $f_{c s}$ values of 13.0 and $10.8 \mathrm{MPa}$ were achieved on the $10 \mathrm{M}-0.30$ RPGMs after exposure to $\mathrm{Na}_{2} \mathrm{SO}_{4}$ solution for 90 and 180 days, respectively. Besides, an increase in the molarity of $\mathrm{NaOH}$ had a negative influence on the residual $f_{c s}$ of the RPGMs as reported in the results of the acid environment. The lowest residual $f_{c s}$ of $17.9 \%$ was calculated for the $15 \mathrm{M}-0.05$ RPGMs after exposure to $\mathrm{Na}_{2} \mathrm{SO}_{4}$ solution for 180 days. Additionally, the residual $f_{c s}$ values of the RPGMs after exposure to $\mathrm{Na}_{2} \mathrm{SO}_{4}$ solution were slightly higher than the values after exposure to $\mathrm{HCl}$ solution. 


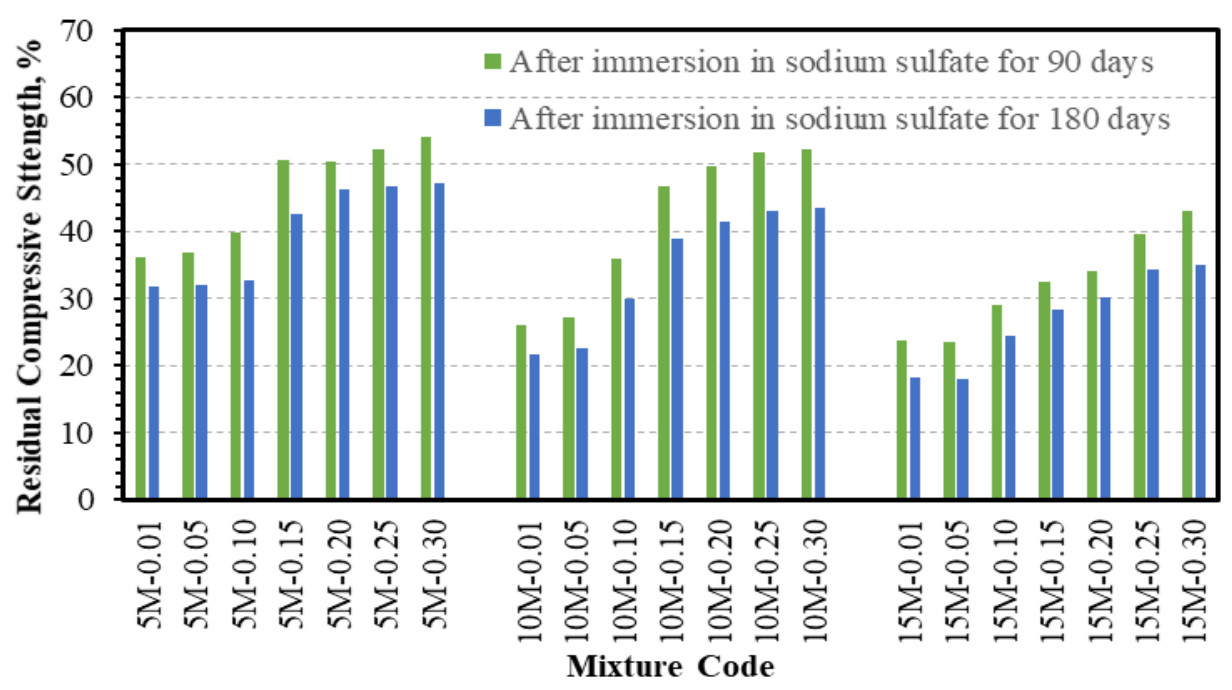

Figure 6. Residual compressive strengths of RPGMs after exposure to $\mathrm{Na}_{2} \mathrm{SO}_{4}$.

The residual $f_{c s}$ percentages and final $f_{c s}$ values of the RPGMs after immersion in $5 \% \mathrm{MgSO}_{4}$ solution for 90 and 180 days are given in Figure 7 and Table 4, respectively. While the lowest residual $f_{c s}$ of $17.4 \%$ was seen on the 15M-0.01 RPGMs after immersion in the solution for 180 days, the highest $f_{c s}$ of $46.8 \%$ was observed on the $5 \mathrm{M}$ 0.25 RPGMs at the same condition. As seen in the figure, the residual $f_{c s}$ percentages of the RPGMs increased with the increasing BFS content as observed after exposure to $\mathrm{HCl}$ and $\mathrm{Na}_{2} \mathrm{SO}_{4}$ solutions. Better activation of BFS at lower $\mathrm{NaOH}$ content also increased the residual $f_{c s}$ percentages of the RPGMs in the series of $5 \mathrm{M}$ with respect to the other series. Besides, the durability test results indicate that the $\mathrm{HCl}(\mathrm{pH}=2)$ and $5 \% \mathrm{MgSO}_{4}$ solutions had a more detrimental effect on the $f_{c s}$ of the RPGMs than the $5 \% \mathrm{Na}_{2} \mathrm{SO}_{4}$ solution. The major loss in the $f_{c s}$ of the RPGMs was noted after immersion in the acid or sulfate solutions for 90 days. The decrease in the $f_{c s}$ values of the mortars was more limited from 90 to 180 days than from 0 to 90 days.

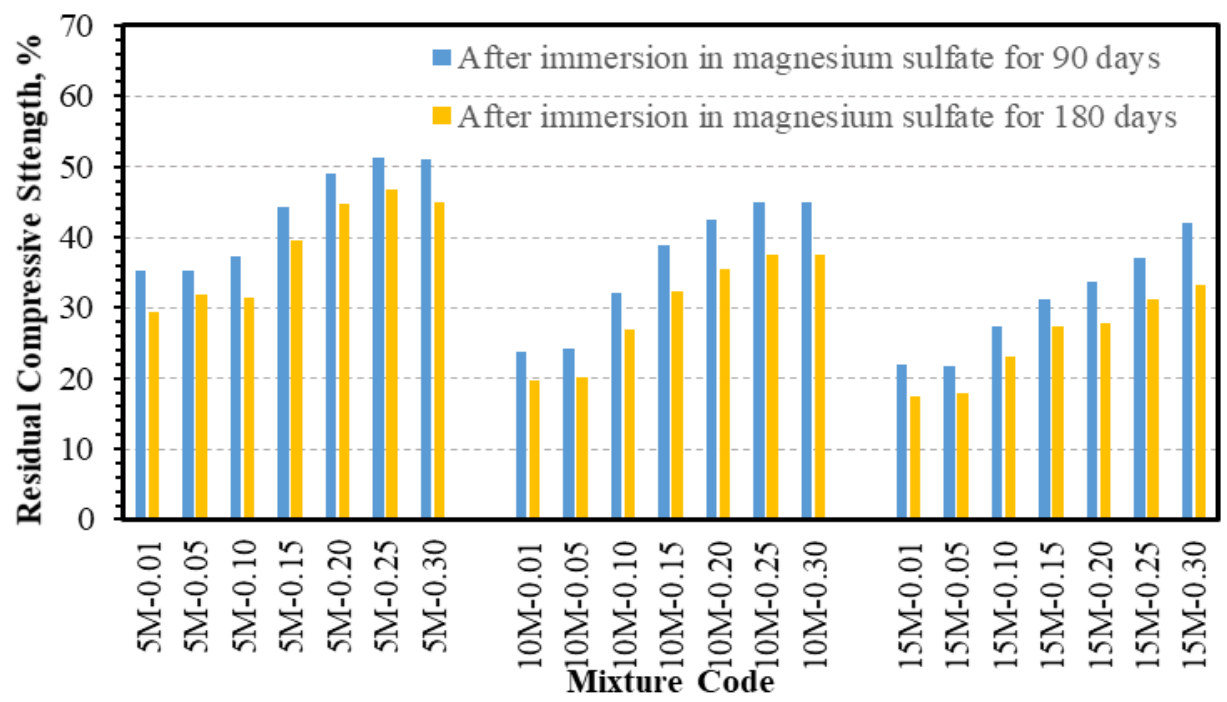

Figure 7. Residual compressive strengths of RPGMs after exposure to $\mathrm{MgSO}_{4}$. 


\section{CONCLUSION}

The mechanical and durability properties of blast furnace slag incorporated ground perlite-based geopolymer mortars are investigated in this study. With regard to the analysis of results obtained from this work, the following conclusions are revealed from these results.

- The optimum BFS content in the ground perlite-based geopolymer mortars is variable dependent on the molarity of $\mathrm{NaOH}$. The best results in respect of mechanical and durability properties were achieved on the 10M-0.30 mortars.

- The effect of $\mathrm{NaOH}$ concentration changed with the precursor combination $\left(\mathrm{CaO} / \mathrm{SiO}_{2} \mathrm{ratio}\right)$. The mechanical properties of ground perlite-based geopolymer mortars improved by increasing $\mathrm{NaOH}$ molarity. The optimum $\mathrm{NaOH}$ molarity was determined as $10 \mathrm{M}$ for the blast furnace slag incorporated ground perlite-based geopolymer mortars.

- Water absorption capacity of ground perlite-based geopolymer mortars decreased by increasing the blast furnace slag content independent of the $\mathrm{NaOH}$ molarity. The influence of blast furnace slag was more distinct at low $\mathrm{NaOH}$ content.

- The flexural strength/compressive strength ratio of the ground perlite-based geopolymer mortars decreased gradually with increasing the blast furnace slag content.

- Blast furnace slag incorporation in the ground perlite-based geopolymer mortars increased the acid and sulfate durability of these mortars, significantly.

- Magnesium sulfate and hydrochloric acid had a more detrimental influence on the strength of ground perlite-based geopolymer mortars with respect to the sodium sulfate.

\section{REFERENCES}

ASTM C 597, 2016. Standard Test Method for Pulse Velocity through Concrete, American Society for Testing and Materials, West Conshohocken, PA, USA.

ASTM C 642-06, 2006. Standard test method for density, absorption, and voids in hardened concrete, PP 1- 3, ASTM International, Pennsylvania, United States,

Atabey, İ. İ.\&Oztürk, Z. B. 2021. Investigation of Usability of Ceramic Sanitary ware Wastes in Geopolymer Mortar Production. International Journal of Engineering Research and Development. 13(1): 212-219. https://doi.org/10.29137/umagd.782733

Aydın, S. 2013. A ternary optimisation of mineral additives of alkali activated cement mortars. Construction and Building Materials. 43: 131-138. https://doi.org/10.1016/j.conbuildmat.2013.02.005

Brough, A. R. \& Atkinson, A. 2002. Sodium silicate-based, alkali-activated slag mortars: Part I. Strength, hydration and microstructure. Cement and Concrete Research. 32(6): 865-879. https://doi.org/10.1016/S0008-8846(02)00717-2

Celikten, S. \&Isikdag, B. 2020. Strength development of ground perlite-based geopolymer mortars. Advances in Concrete Construction. 9(3): 227-234.

Çelikten, S., \&Işıkdağ, B. 2021. Properties of geopolymer mortars derived from ground calcined perlite and $\mathrm{NaOH}$ solution. European Journal of Environmental and Civil Engineering, 1-15. https://doi.org/10.1080/19648189.2021.1879939

Çelikten, S., Sarıdemir, M. \&Deneme, İ. Ö. 2019. Mechanical and microstructural properties of alkaliactivated slag and slag+ fly ash mortars exposed to high temperature. Construction and Building Materials. 217: 50-61. https://doi.org/10.1016/j.conbuildmat.2019.05.055 
Cho, Y. K., Yoo, S. W., Jung, S. H., Lee, K. M. \& Kwon, S. J. 2017. Effect of $\mathrm{Na} 2 \mathrm{O}$ content, $\mathrm{SiO}_{2} / \mathrm{Na}_{2} \mathrm{O}$ molar ratio, and curing conditions on the compressive strength of FA-based geopolymer. Construction and Building Materials. 145: 253-260.

de Oliveira, A. G., JandornoJr, J. C., da Rocha, E. B. D., de Sousa, A. M. F. \& da Silva, A. L. N. 2019. Evaluation of expanded perlite behavior in PS/Perlite composites. Applied Clay Science. 181: 105223. https://doi.org/10.1016/j.clay.2019.105223

El Hafid, K., Hajjaji, M. \& El Hafid, H. 2017.Influence of $\mathrm{NaOH}$ concentration on microstructure and properties of cured alkali-activated calcined clay, Journal of Building Engineering. 11: 158-165. https://doi.org/10.1016/j.jobe.2017.04.012.

EN 196-1, 2016. Methods of Testing Cement-Part 1: Determination of Strength, European Committee for Standardization (CEN),

Erdogan, S. T. 2015. Properties of ground perlite geopolymer mortars. Journal of Materials in Civil Engineering. 27(7): 04014210. https://doi.org/10.1061/(ASCE)MT.1943-5533.0001172

Gao, X., Yu, Q. L., Yu, R. \&Brouwers, H. J. H. 2017. Evaluation of hybrid steel fiber reinforcement in high performance geopolymer composites. Materials and Structures. 50(2): 165. https://doi.org/10.1617/s11527017-1030-x

Kaya, M. 2021. The effect of silica fume and micro $\mathrm{SiO}_{2}$ additive on the strength properties in kaolin based geopolymer mortars.NiğdeÖmerHalisdemir University Journal of Engineering Sciences, 11.https://doi.org/10.28948/ngumuh.886863

Lafhaj, Z. \&Goueygou, M. 2009. Experimental study on sound and damaged mortar: Variation of ultrasonic parameters with porosity. Construction and Building Materials. 23(2): 953-958. https://doi.org/10.1016/j.conbuildmat.2008.05.012

Li, C., Sun, H. \& Li, L. 2010. A review: The comparison between alkali-activated slag ( $\mathrm{Si}+\mathrm{Ca}$ ) and metakaolin ( $\mathrm{Si}+\mathrm{Al}$ ) cements. Cement and Concrete Research. 40(9): 1341-1349. https://doi.org/10.1016/j.cemconres.2010.03.020

Luna Galiano, Fernández Pereira, Y. C. \&Izquierdo. M. 2016. Contributions to the study of porosity in fly ash-based geopolymers. Relationship between degree of reaction, porosity and compressive strength, Materiales de Construccion. 66: 324.https://doi.org/10.3989/mc.2016.10215.

Mendes, J. C., Barreto, R. R., Costa, L. C. B., Brigolini, G. J. \&Peixoto, R. A. F. 2020. Correlation Between Ultrasonic Pulse Velocity and Thermal Conductivity of Cement-Based Composites. Journal of Nondestructive Evaluation. 39(2). https://doi.org/10.1007/s10921-020-00680-7

Part, W.K., Ramli, M. \&Cheah, C.B. 2015.An overview on the influence of various factors on the properties of geopolymer concrete derived from industrial by-products, Construction and Building Materials. 77: 370395. https://doi.org/10.1016/j.conbuildmat.2014.12.065.

Praveen Kumar, V. V., Prasad, N. \&Dey, S. 2019. Influence of metakaolin on strength and durability characteristics of ground granulated blast furnace slag based geopolymer concrete. Structural Concrete. https://doi.org/10.1002/suco.201900415

Provis, J. L., Myers, R. J., White, C. E., Rose, V. \& Van Deventer, J. S. 2012. X-ray microtomography shows pore structure and tortuosity in alkali-activated binders. Cement and Concrete Research. 42(6): 855864. https://doi.org/10.1016/j.cemconres.2012.03.004

Ranjbar, N., Talebian, S., Mehrali, M., Kuenzel, C., Metselaar, H. S. C. \&Jumaat, M. Z. 2016. Mechanisms of interfacial bond in steel and polypropylene fiber reinforced geopolymer composites. Composites Science and Technology. 122: 73-81. https://doi.org/10.1016/j.compscitech.2015.11.009 
Sarıdemir, M. \&Çelikten, S. 2020. Investigation of fire and chemical effects on the properties of alkaliactivated lightweight concretes produced with basaltic pumice aggregate. Construction and Building Materials. 260: 119969. https://doi.org/10.1016/j.conbuildmat.2020.119969

Sun, Q. Zhu, H. Li, H. Zhu, H. Gao, M. 2018. Application of response surface methodology in the optimization of fly ash geopolymer concrete. RevistaRomana de Materiale.48(1): 45-52.http://solacolu.chim.upb.ro/p4552.pdf

Taxiarchou, M., Panias, D., Panagiotopoulou, C., Karalis, A. \&Dedeloudis, C. 2013. Study on the suitability of volcanic amorphous aluminosilicate rocks (perlite) for the synthesis of Geopolymer-based concrete. In Geopolymer Binder Systems. ASTM International. https://doi.org/10.1520/STP156620120077

Temuujin, J., Rickard, W. \& Van Riessen, A. 2013. Characterization of various fly ashes for preparation of geopolymers with advanced applications. Advanced Powder Technology. 24(2): 495-498. https://doi.org/10.1016/j.apt.2013.01.013

Thaarrini, J. \&Ramasamy, V. 2016. Properties of foundry sand, ground granulated blast furnace slag and bottom ash based geopolymers under ambient conditions. PeriodicaPolytechnica Civil Engineering. 60(2): 159-168. https://doi.org/10.3311/PPci.8014

Timakul, P., Rattanaprasit, W. \&Aungkavattana, P. 2016. Improving compressive strength of fly ash-based geopolymer composites by basalt fibers addition. Ceramics International. 42(5): 6288-6295. https://doi.org/10.1016/j.ceramint.2016.01.014

TS EN 1015-11, 2000. Methods of test for mortar for masonry-part 11: determination of fexural and compressive strength of hardened mortar. Turkish Standards Institution, Ankara, Turkey.

Yurt, U. \&Emiroğlu, M. 2020. The Effects of Curing Condition on Geopolymers Incorporating Zeolit. Academic Platform Journal of Engineering and Science. 8(2): 396-402. https://doi.org/10.21541/apjes.688186

Yusuf, M. O., Johari, M. A. M., Ahmad, Z. A. \&Maslehuddin, M. 2014. Strength and microstructure of alkali-activated binary blended binder containing palm oil fuel ash and ground blast-furnace slag. Construction and Building Materials. 52: 504-510.https://doi.org/10.1016/j.conbuildmat.2013.11.012 